$\mathrm{H}_{2}$ blockers have recently been advocated for treating anaphylaxis and are effective when anaphylaxis is restricted to the skin. A few case reports have recorded their efficacy in hypotension. Until their role has been established they are not drugs of first choice ${ }^{8}$; they may help in protracted cases when release of histamine may be continuing-in such patients $\mathrm{H}_{2}$ blockers seem to produce a more stable blood pressure. Anaphylaxis may also be associated with heart failure, particularly as a secondary effect in patients with cardiac disease. ${ }^{4}$ Despite the well known effects of anaphylactic mediators on the heart evidence of heart failure in patients without cardiac disease during anaphylaxis is extremely rare, although it occurs. ${ }^{9}$ In protracted anaphylaxis there is a case for measuring filling pressures or imaging the heart.

Adrenaline is a valuable drug in managing acute, severe anaphylaxis. Factors such as the severity of the condition, the doctor's experience, difficulty of venous access, and the ability to measure the effect of treatment are important in selecting a route of administration. In severe anaphylaxis adrenaline by any route is better than none.

MALCOLM FISHER

Royal North Shore Hospital,

Head of Intensive Therapy Unit

St Leonards,

New South Wales 2065,

Australia

1 Soreide E, Buxrud T, Harboe S. Severe anaphylactic reactions outside hospital: etiology, symptom and treatment. Acta Anaesthesiol Scand 1988;32:339-42.

Fisher M. Anaphylaxis. Dis Mon 1987;33:433-79. 2 Fisher M. Anaphylaxis. Dis Mon 1987;33:433-79.
3 Barach EM, Nowak RM, Lee TG, Tomlanovich MC. Epinephrine for treatment of anaphylactie
shock. JAMA 1984;251:2118-22.

4 Fisher MM. Clinical observations on the pathophysiology and treatment of anaphylactic cardio $\overline{\bar{A}}$ vascular collapse. Anaesth Intensive Care 1986;14:17-21.

5 Stark BJ, Sullivan TJ. Biphasic and protracted anaphylaxis. F Allergy Clin Immunol 1986;78:76-83. 6 Waldhausen E, Keser G, Marquardt B. Der anaphylaktische Schock. Anaesthesist 1987;36:150-8.

7 Fisher $M$. Blood volume replacement in acute anaphylactic cardiovascular collapse related to anaesthesia. Br f Anaesth 1977;49:1023-6.

8 Kelly JS, Prielipp RC. Is cimetidine indicated in the treatment of acute anaphylactic shock? Anest 2 Analg 1990;71:104-5.

9 Raper RF, Fisher MM. Profound reversible myocardial depression after anaphylaxis. Lancet 1988; ;:386-8

\title{
Familial Alzheimer's disease: second gene locus located
}

\section{Markers for cases of early onset familial disease may soon be available}

Alzheimer's disease is the main cause of neurodegeneration in developed countries, affecting an estimated 750000 people in Britain and four million in the United States. The characteristic plaque in brains of patients with Alzheimer's disease contains $\beta$ amyloid protein, which is cleaved from the amyloid precursor protein.

The disease is undoubtedly aetiologically heterogeneous, and the search for clinical or pathological features demarcating subgroups with separate causes has in general been unrewarding. A family history and age of onset are the most useful clinical features that can be related to aetiology. Early onset familial Alzheimer's disease (arbitrarily defined as that below age 65) seems to be transmitted as an autosomal dominant. Genetic studies with early onset familial disease initially showed linkage to chromosome $21,{ }^{1}$ and the identification of mutations of the gene coding for the amyloid precursor protein on that chromosome followed. ${ }^{2-5}$

The inheritance of one of these rare mutations completely predicts the occurrence of the disease. These mutations occur at either end of the $\beta$ amyloid sequence ${ }^{5}$ in the larger amyloid precursor protein molecule. By as yet undetermined mechanisms their presence causes the production of $\beta$ amyloid in an insoluble form. The demonstration that amyloid itself can initiate the disease process and is not just an "innocent bystander" has prompted the theory that in some way mismetabolism of amyloid precursor protein is always the primary event in Alzheimer's disease. Mutations of the amyloid precursor protein, however, account for probably less than a quarter of early onset familial Alzheimer's disease.

Aided by the human genome project, ${ }^{6}$ researchers turned their attention to locating other genes predisposing to early onset Alzheimer's disease. In a recent issue of Science Schellenberg and colleagues reported the identification of a second gene for early onset Alzheimer's disease linked to markers on chromosome $14 .{ }^{7}$ In their dataset eight out of nine families with early onset disease and differing genetic backgrounds showed evidence of linkage. My group's analysis of nine British families is consistent with linkage to the middle long arm of chromosome $14 .^{8}$

Although the odds for linkage are overwhelmingly in favour of a gene on chromosome 14, further localisation isp subject to accurate assessment of genetic heterogeneity in families without mutations of amyloid precursor protein. One key problem arises because statistically it is possible to detecte linkage in several families collectively without being able tow show that all or any families are individually linked. The fact, however, that most of the families analysed by these two groups ( 16 out of 18 in total) are consistent with linkage at the chromosome 14 locus suggests that this linkage will account for most very early familial cases. If this is so, genetic rislo calculations with markers for either amyloid precursor syn $\overrightarrow{\overrightarrow{0}}$ drome or markers on chromosome 14 are imminent in early onset familial Alzheimer's disease.

The hypothesis that amyloid is intimately related to the disease process will be tested when the chromosome 14 gene is identified. This will shed considerable light on the ides that amyloid mismetabolism is the primary error in the common, non-genetic cases of the disease. Several genes localised to chromosome 14 influence the metabolism os processing of amyloid precursor protein, and further genetico analysis will define which ones are important. Previous studies have excluded members of the cathepsin family, a尺 least one of which is known to metabolise amyloid precursoro protein.

This research holds out the prospect of improving ou understanding of the pathogenic pathways that lead to Alzheimer's disease. Whatever its cause(s), the disease is clinically and neuropathologically homogeneous; therefore the pathological pathways resulting from mutations in either amyloid precursor protein or the second locus must, at somet point, converge. Better knowledge of how these two patho genic pathways relate should improve our understanding of the common late onset form of the disease and may hasten the development of treatments.

\section{Codirector}

MIKE MULLAN

Alzheimer's Disease Research Laboratories,

Department of Psychiatry,

University of South Florida,

Tampa, Florida 33613

USA 
1 St George Hyslop PH, Tanzi RE, Polinsky RJ, Haines JL, Nee L, Watkins PC, et al. The genetic defect causing familial Alzheimer's disease maps on chromosome 21. Science 1987;235:885-90. 2 Goate A, Chartier Harlin MC, Mullan M, Brown J, Crawford F, Fidani L, et al. Segregation of a missense mutation in the amyloid precursor protein gene with familial Alzheimer's disease. Nature 1991;349:704-6.

3 Chartier Harlin MC, Crawford F, Houlden H, Warren A, Hughes D, Fidani L, et al. Early onset Alzheimer's disease caused by mutations at codon 717 of the $\beta$-amyloid precursor protein gene. Nature 1991;353:844-6.

4 Murrell J, Farlow M, Ghetti B, Benson M. A mutation in the amyloid precursor protein associated with hereditary Alzheimer's disease. Science 1991;254:97-9.
5 Mullan $\mathrm{M}$, Crawford $\mathrm{F}$, Axelman $\mathrm{K}$, Houlden $\mathrm{H}$, Lilius $\mathrm{L}$ Winblad $\mathrm{B}$, et al A pathogenic mutation for probable Alzheimer's disease in the amyloid precursor protein gene at the $N$ terminus of for probable Alzheimer's disease in the

NIH/CEPH Collaborative Mapping Group. A comprehensive genetic linkage map of the human genome. Science 1992;258:67-86.

Schellenberg G, Bird T, Wijsman E, Orr HT, Anderson L, Nemens E, et al. Genetic linkage evidence for a familial Alzheimer's disease locus on chromosome 14. Science 1992;258:668-71.

8 Mullan M, Houlden H, Windelspecht M, Fidani L, Lombardi C, Diaz P, et al. A major locus for familial early onset Alzheimer's disease is on the long arm of chromosome 14, proximal to $\alpha$-antichymotrypsin. Nature Genetics (in press).

\title{
Asking patients about their treatment
}

\author{
Why their answers should not always be taken at face value
}

Patients' views on health care are sought for various reasons. They form a crucial component of research into the outcome of clinical interventions and help improve our understanding of how people cope with being ill or strive to remain well. Recently, patients' views have received growing acknowledgment in the planning and delivery of health care, most notably in Working for Patients and the patient's charter. Developing methods for involving patients in the evaluation of health care is regarded as a priority in clinical audit. ${ }^{1}$

In eliciting the views of patients two assumptions are crucial: firstly, that patients want their views taken into account and, secondly, that such views are trustworthy indicators of a patient's health or health care. The first assumption implies that patients' views should be balanced and well informed. This in turn requires that patients should have access to all the information they require and should participate as actively as possible in the management of their illnesses. Although a sound principle to follow, this cannot be applied fully under all circumstances to all patients. For example, older people express a weaker preference for personal involvement in decisions about their medical care than younger people. ${ }^{2}$ Patients' expressed wishes for involvement decline with increasing severity of their illness, ${ }^{23}$ although this probably relates more to their perception of the severity of their disease than to objective, "disease" variables. ${ }^{4}$ Ethnic group and cultural background are also likely to be important. ${ }^{5}$ Other factors may operate-for example, some patients adopt denial to cope with their illness, ${ }^{67}$ and they commonly find detailed inquiry about their illness intrusive or even distressing.

How trustworthy are patients' accounts of their health or illness? For example, how do they compare with other variables, particularly those defined by the patients' professional carers? Where disease related variables are available they do not necessarily accord with patients' views. For example, in arthritis, patients' assessments of their disability and functional status correlate only weakly with objectively obtained measures of these. They are more strongly linked with psychological factors such as patients' perceptions of how controllable their symptoms will be. ${ }^{8}$ Similar observations have been made in other illnesses, including cancer ${ }^{9}$ and chronic renal failure. ${ }^{10}$ This is hardly surprising - to a patient an illness is an experience, not easily reduced to a list of variables measured in the laboratory or clinic. Attempting to define and understand such experiences forms a major focus of the work of general hospital psychiatrists and health psychologists, who have much to contribute to the assessment of patients' views from their research and clinical work.

If patients' views are not always reliable is it possible to predict when they should be interpreted with caution? Denial is likely to be important in only a few cases. Of greater importance quantitatively is the presence of affective dis- turbance. Symptoms of depression or anxiety occur in up to $60 \%$ of people with serious physical illnesses. ${ }^{11}$ These rates overestimate the prevalence of clinically important affective disorder as such symptoms in physically ill people are often transient. Even such transient symptoms, however, are associated with the distorted patterns of thinking that are characteristic of depression or anxiety. ${ }^{1213}$ Symptoms of depression influence patients' perception of disability and pain $^{814}$ and their coping strategies, ${ }^{15}$ which in turn can affect overall adjustment to illness. ${ }^{16}$ Depression and anxiety can also bias patients' perceptions of their medical care ${ }^{14}{ }^{17}$ and are therefore likely to affect their desire for involvement in decisions affecting their management. Affective disturbance leads to a systematic bias in patients' perceptions and beliefs, which is likely to distort all types of self ratings, including reported symptoms, functional status, overall health, and satisfaction.

Some measures of global satisfaction for assessing the outcome of intervention were developed for use in (healthy) community samples. ${ }^{18}$ In such populations affective symptoms, particularly transient ones, are far less common than they are among physically ill people. Such scales, whose ratings correlate significantly with measures of depression, ${ }^{19}$ have yet to be properly validated in samples of patients to whom they have been applied. Other scales intended to provide global outcome ratings in the physically ill, such as the SF-36 questionnaire, ${ }^{20}$ include items that are likely to elicit different answers if depression is present. Again, invalid results are more likely from patients with serious physical illness than from patients drawn from general practice lists. ${ }^{21}$ For people with HIV infection, overall self ratings on the SF36. questionnaire correlate strongly with physical symptoms, suggesting that this questionnaire may be a valid measure of outcome. ${ }^{22}$ All scores from the SF-36 questionnaire, however, correlate significantly with self ratings of depression, and scores on the scales assessing psychological aspects of quality of life do not correlate with disease progression (M Dayer et al, unpublished observations).

Wells et al have argued that patients make similar demands for health care whether they are physically ill or depressed and that the basis of these demands can therefore be ignored..$^{23}$ In this instance, demands are very different from needs. Patients with physical illnesses who are anxious or depressed may ask for more frequent review in the outpatient clinic and may even be satisfied with their care if this can be arranged. Such management fails, however, to meet one of their needsnamely, the management of their affective disorder.

Although the growing interest in patients' views should be welcomed, comments and questionnaire ratings may not necessarily be adequate end points in themselves. In clinical audit, doctors rightly insist that managers, politicians, and others must understand how data are collected to judge their 